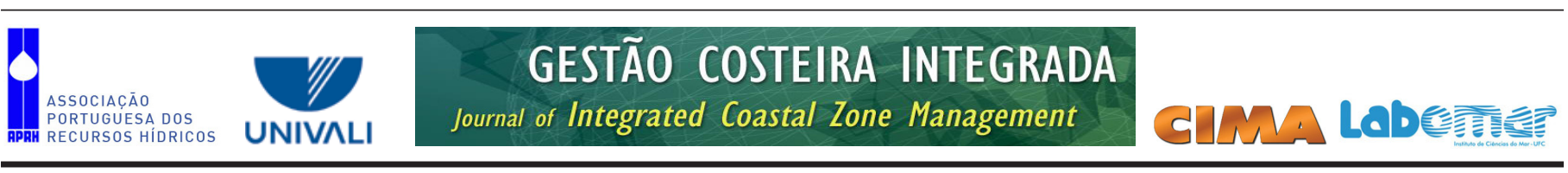

http://www.aprh.pt/rgci/pdf/rgci-448_Loitzenbauer.pdf | DOI:10.5894/rgci448

\title{
A Faixa Terrestre da Zona Costeira e os Recursos Hídricos na Região Hidrográfica do Atlântico Sul, Brasil *
}

\author{
The terrestrial coastal zone and the water resources in the South Atlantic \\ Hydrographical Region, Brazil
}

\author{
Ester Loitzenbauer ${ }^{\circledR, 1}$, Carlos André Bulhões Mendes ${ }^{1}$
}

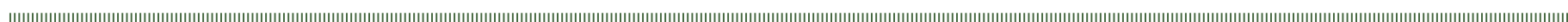

\section{RESUMO}

No Brasil, o Plano Nacional de Gerenciamento Costeiro II delimita a faixa terrestre da zona costeira, utilizando, principalmente, critérios administrativos, os limites municipais. Contaminação das águas costeiras e aumento da intrusão salina são exemplos de problemas que podem surgir quando a delimitação da área de gestão náo contempla o funcionamento dos sistemas físicos, como as bacias hidrográficas. Partindo da premissa de que existe uma relação de causa e efeito entre o uso da terra na bacia e a qualidade ambiental costeira, o presente estudo analisa a delimitaçáo da zona costeira terrestre da Região Hidrográfica do Atlântico Sul. A partir do confronto entre a definição federal e a dos estados com os limites da bacia que drena para o oceano, propostas são elaboradas para os estados que apresentam deficiências na integração dos processos físicos com as fronteiras de gestáo costeira. Observa-se que os estados, muitas vezes, não utilizam a mesma definição proposta pela esfera federal. Os estados do Rio Grande do Sul, Paraná e São Paulo incluem, de alguma forma, na sua definição de zona costeira terrestre, o critério da bacia de drenagem. Somente o estado de Santa Catarina náo o considera, e, além disso, usa uma definiçáo que diminui a delimitação nacional. O estado de Santa Catarina deve aprimorar a sua definição. Em primeiro lugar, através da inclusão dos municípios excluídos da definição nacional. Em segundo lugar, por meio da criação de uma zona de influência costeira, que náo faz parte da zona costeira propriamente dita, mas que seria uma zona para a integraçáo das políticas ambientais, sobretudo da gestáo costeira com os recursos hídricos. O estado do Rio Grande do Sul, apesar de considerar a bacia de drenagem na sua definição de zona costeira, não considera os limites municipais, preconizados pela definição nacional. As definiçôes dos estados do Paraná e de São Paulo estáo aceitáveis, considerando suas características físicas. Observa-se a tendência de utilizar definiçóes mais específicas no nível estadual. Contudo, dos estados analisados, não há nenhuma que possa ser extrapolada para os outros estados. Cada estado deve considerar delimitaçóes mais específicas em funçáo das suas particularidades físicas, sobretudo a área da bacia de drenagem costeira.

Palavras chave: Gerenciamento Costeiro, Fronteiras de Gestão, Gestão Integrada de Recursos Hídricos, bacia de drenagem.

\section{ABSTRACT}

The Brazilian National Coastal Management Plan II defines the terrestrial stripe of coastal zone using mainly administrative criteria, namely the municipal boundaries. Pollution of coastal waters and increase in saltwater intrusion are examples of problems that may occur when the management

@ - correspondingauthor

1 - Universidade Federal do Rio Grande do Sul, Instituto de Pesquisas Hidráulicas (IPH/UFRGS), Av. Bento Gonçalves, 9500 - CEP $91501-970$ - Caixa Postal15029-Porto Alegre, RS, Brasil.e-mails: Loitzenbauer - ester_loi@yahoo.com.br; Mendes - mensdes@iph.ufrgs.br 
boundaries does not consider the physical systems, such as the catchment basin. The hydrographical basin is the area that drains the rainwater to the watercourses, following the geographic and topographic environmental characteristics. Thus, the hydrographical basin can be set as the unit of environmental management. Assuming that there is a cause-effect interaction between the land use in the basin and the coastal environmental quality, this article does an analysis of the terrestrial coastal zone definition in the Brazilian South Atlantic Hydrographical Region. The federal coastal definition is compared with the states definition and with the hydrographical basin that drains directly to the ocean. Then proposals for new coastal zone boundaries are made for the states that have deficiencies in integrating the physical boundaries in the coastal management boundaries. There are conflicts regarding the territorial cuts in the integrated management in Brazil. The water resource policy uses the hydrographical basin as unit; the environmental policy uses the territorial limits of the federal entities (union, states and municipality) and the coastal management uses the Coastal Management National Plan definition and the municipalities as units. In this context, this article aims to propose a manner to find an intersection of these territorial cuts, especially between water resources and the coastal zone. The concept used was that the boundaries of coastal zone can be the basis for the integration of environmental policies. It was noted that states often do not apply the same definition as the federal government. The states of Rio Grande do Sul, Parana and São Paulo somehow include in their coastal zone definition the criterion of drainage basin. Only the state of Santa Catarina does not. Furthermore, it uses a smaller definition than the national one. The Santa Catarina state must improve its coastal definition. Firstly, through the inclusion of municipalities excluded from the national definition, which has in their territory activities of great environmental impact (coal mining). Second, by creating a zone of coastal influence (ZCI), which is not part of the coastal zone itself, but an area for the integration of environmental policies, especially coastal and water resources. The ZCI could be defined based in the physical dynamics of the environmental and the drainage basin. The management strategy of the ZCI will be different from the coastal zone itself. It will not be under the rules of the national coastal management plan, i.e., having a municipal plan of coastal management, but will be an area where the land and water use should considerer the consequences to the coastal zone. Environmental licensing and water permits in the ZCI should observe the cause-effect relation in the coastal zone. The water permits must control the freshwater inflow necessary to the estuarine ecosystems and the natural saltwater intrusion in the estuary. The environmental licensing and the qualitative water permits must be used to maintain a good water quality in the coastal zone. The ZCI could be defined based on the Kjerfve (1987) estuary's definition - in which the upper estuary is bounded in the tidal penetration. Then, the ZCI would be the area between the upper limit of the estuary and the coastal zone (defined by the National Plan of Coastal Management). Although the state of Rio Grande do Sul observes the catchment basin in its definition, it do not consider the municipality limits, as recommended by the national government. The management process becomes complicated when the instruments of coastal management can be applied only in part of the municipality territory. The Rio Grande do Sul definition should be improved by including the municipality criterion. The intersection between the municipality and the basin criteria should be done by rounding off. The municipalities with an area of more than $50 \%$ inside the coastal drainage basin is included in the coastal zone, and the ones with less than 50\% of the area will be not coastal zone. The Parana and São Paulo coastal zone definitions are considered acceptable as it includes the catchment basin and the municipality criteria. It is observed a tendency to use more specific definitions at the state level. However, in the states analyzed, there is no definition that can be extrapolated to other states. Each state should have a specific definition in terms of their physical peculiarities, especially the size of the coastal catchment. In the states of Rio Grande do Sul, Parana and São Paulo the integrated coastal and water resources management should be done in the coastal zone, and there is no need for a zone of integration. Outside the coastal zone, the instruments of water resources and environmental management should be applied as usual.

Keywords: Coastal Management, Management Boundaries, Integrated Water Resources Management, drainage basin.

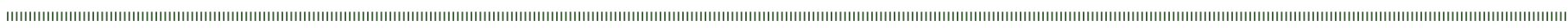

\section{INTRODUÇÁO}

A ocupação da zona costeira no Brasil vem crescendo, coincidindo com processos de intensa urbanização, atividade portuária e industrial e exploração turística em larga escala (MMA, 2008). Mas não apenas a ocupação humana das zonas costeiras as tem afetado. A ameaça pelo uso descontrolado da terra pode estar localizada longe da costa, a montante. Os problemas da zona costeira náo podem ser resolvidos com o seu gerenciamento apenas, pois a zona costeira é parte essencial da bacia hidrográfica (Monteiro \& Marchand, 2009). Destaca-se, assim, a importância da gestão integrada, principalmente entre os recursos hídricos e a zona costeira.

A gestão integrada começa com a definição dos limites de manejo, que devem corresponder às unidades físicas ou ecológicas da costa (Clark, 1996). Entretanto, a delimitação exata dos limites é difícil devido à natureza dinâmica da costa. Uma definição básica de zona costeira é a interface ou zona de transição ondeparte do continente é a fetada pela proximidade com o mar e onde parte do oceano é a fetada devido a sua proximidade com o continente (Sorenson \& McCreary, 1990).

No Brasil, o Plano Nacional de Gerenciamento Costeiro - PNGC II define a zona costeira como o espaço geográfico de interação do ar, do mar e da terra, incluindo seus recursos ambientais, abrangendo uma faixa marítima e outra terrestre. A faixa marítima (ou oceânica) se estende mar afora, distando 12 milhas marítimas das Linhas de Base estabelecidas de acordo com a Convenção das Naçóes Unidas sobre o Direito do Mar de 1982, compreendendo a totalidade do Mar Territorial. A faixa terrestre (ou continental) é formada pelos municípios que sofrem influência dos fenômenos ocorrentes na zona costeira (atualização pelo Dec. Federal $\mathrm{n}^{\circ}$ 5.300/2004), por exemplo: defrontantes com o mar; estuarino-lagunares; não defrontantes com o mar, porém localizados nas regiôes metropolitanas litorâneas ou distantes até cinquenta quilômetros da linha da costa, e que contemplem, em seu território, atividades ou infraestruturas de grande impacto ambiental.

Essa definição ampla se complementa através da Relação dos municipios abrangidos pela faixa terrestre da zona costeira, presente no Anexo B do PNGC II (Res. CIRM ${ }^{1} n^{\circ}$ 005/1997). $\mathrm{O}$ mesmo anexo prevê a atualização da lista dos municípios, assim como o Dec. Federal no 5.300/2004, que institui a

1 - Comissão Interministerial para os Recursos do Mar. 
atualização anual, sob responsabilidade do Ministério do Meio Ambiente. Entretanto, essa atualização não é realizada periodicamente, e quase todos os estados brasileiros possuem dados defasados.

Também no Dec. Federal no 5.300/2004, dois pontos interessantes são estabelecidos com relação à definição de zona costeira. O primeiro é que os Estados podem encaminhar ao Ministério do Meio Ambiente propostas de alteração da relação dos municípios abrangidos pela faixa terrestre da zona costeira, justificando a inclusão ou retirada da relação. Contudo, na prática, observam-se alguns estados apresentando definiçóes próprias, algumas até não considerando os limites municipais e sendo utilizadas para a gestão costeira estadual, sem nenhuma preocupação com a esfera federal ou a legislação federal relevante. Um exemplo disso é o estado do RS, onde o GERCO estadual utiliza um critério que não é muito claro, considerando de alguma forma a bacia que drena para o oceano e para a Lagoa dos Patos e desconsiderando os limites municipais (FEPAM, s/d). Cabe ao Ministério do Meio Ambiente maior cobrança com relação ao gerenciamento costeiro estadual e à fiscalização dos critérios utilizados para a definição da zona costeira.

O segundo item é a possibilidade dos municípios de pleitear, junto aos estados, a sua intenção de integrar a Relação dos municípios abrangidos pela faixa terrestre da zona costeira, com a devida justificativa da razão de pretensão. Essa opção é um tanto utópica. Ao se tornar um município costeiro, maiores responsabilidades serão atribuídas, incluindo a observação dos instrumentos de gestáo costeira, como a elaboração de um Plano Municipal de Gerenciamento Costeiro, com o objetivo de implementar a Política Municipal de Gerenciamento Costeiro; fazer parte do Zoneamento Ecológico-Econômico Costeiro (ZEEC); observação das regras de ocupação e uso da terra propostas a nível nacional; entre outras. Isso torna a gestão ambiental mais complexa e cara em nível municipal.

Problemas surgem na definição de zona costeira para um país com tamanha diversidade de costas e nas escalas espaciais dos ecossistemas envolvidos. A natureza dinâmica das costas brasileiras é variável, como, por exemplo, a amplitude de maré, o regime de ventos e de correntes oceânicas. Os sistemas fluviais, que podem se originar muito longe da costa, aumentam a complexidade e a escala da zona costeira. Além disso, os critérios arbitrários (como as 12 milhas náuticas, para a parte marinha) ou as fronteiras administrativas (os municípios, para a parte terrestre) para a delimitação da zona costeira impedem a conservaçáo dos ambientes costeiros e limitam a gestão integrada ao não considerar os limites físicos ou ecológicos.

A definiçấo da faixa marítima da zona costeira como 12 milhas náuticas da costa vem da Convenção das Nações Unidas para o Direito do Mar (UN, 1982), que é amplamente aceita e aplicada no mundo. Contudo, alguns países incluem critérios físicos de maneira complementar, por exemplo, os Países Baixos, que definem Coastal Sea até a isóbata de $20 \mathrm{~m}$ (Lindeboom et al., 2005). Na realidade brasileira, critérios complementares à definição de zona costeira podem favorecer a integração entre a gestão de águas, do território e da zona costeira, incluindo as particularidades do ambiente local e as interações do meio físico, biológico e antrópico.

Beatley et al. (2002) consideram que a porção costeira terrestre deve englobar a área onde o uso da terra a montante influencia a costa, podendo englobar toda a bacia hidrográfica. Da mesma forma, a porção marítima inclui águas rasas e planícies de marés, podendo se estender até águas oceânicas profundas.

A bacia hidrográfica é a área que drena a água que precipita para o curso de água ou para as afluentes, sempre das áreas mais altas para as mais baixas, devido às características geográficas e topográficas (físicas). Dessa forma, a bacia é a unidade para a gestão ambiental, pois tudo o que ocorre nessa área afeta diretamente os corpos hídricos. Por essa razão, a Resolução n ${ }^{\circ} 001$ do Conselho Nacional de Meio Ambiente (CONAMA), que guia a elaboração de Estudos de Impacto Ambiental no Brasil, determina que a área de influência de projeto deve considerar, em todos os casos, a bacia hidrográfica na qual se localiza

Um dos instrumentos da Política Nacional de Recursos Hídricos (PNRH) que pode estabelecer a relação direta entre o uso da água na bacia e as consequências na zona costeira é a outorga. A outorga de uso de recursos hídricos é uma ferramenta útil para definir os limites que cada usuário tem para utilizar o recurso dentro de cada bacia hidrográfica (tanto em termos quantitativos quanto qualitativos), sem comprometer os outros usos e o ecossistema. Contudo, este processo não considera a interaçáa oceano-continente presente na zona costeira.Vários casos têm sido observados em que a falta de regularização da outorga em zonas costeiras tem levado a situaçóes de estresse hídrico e alteração do ecossistema (Genz et al., 2008; Loitzenbauer \& Mendes, 2012).

A outorga em zonas costeiras é um assunto controverso. Há a alegação de que não pode haver outorga em estuários, pois a ingerência do Sistema Nacional de Recursos Hídricos se restringe aos corpos hídricos de água doce. Também, a Agência Nacional de Águas (ANA) entende que, nesses ambientes, as atividades não são passíveis de outorga, por exemplo, e muito menos cobrança pelo uso da água. Contudo, na prática, ocorre a outorga, ignorando o fato de o corpo hídrico em questão ser um corpo estuarino. Nesse contexto, surgiu em 2005 a CTCOST (Câmara Técnica de Integração dos Recursos Hídricos com os Sistemas Estuarinos e Zonas Costeiras) no âmbito do Conselho Nacional de Recursos Hídricos. Contudo, a atuação da CTCOST tem sido limitada e questionada devido a conflitos de domínio e competência - o que compete à gestão de recursos hídricos e o que compete ao gerenciamento costeiro?

A definição das fronteiras da zona costeira no Brasil surge como base para a integração das políticas de gestão ambiental (meio ambiente, recursos hídricos e costeira). Quando se considera a gestáo integrada, o primeiro conflito surge com relação aos recortes territoriais, que são distintos e não coincidem entre si. $\mathrm{O}$ primeiro recorte, relacionado com a gestâo dos recursos hídricos, se assenta na bacia hidrográfica como unidade de planejamento, tanto em nível estadual como federal. A gestáo ambiental se apoia nos limites territoriais dos entes federados, de acordo com suas esferas de competências, e a zona costeira tem como recorte a definição do PNGCII e como unidade os municípios, que definem as restriçóes de uso do solo através dos planos diretores.

Nesse contexto, este estudo trata de propor subsídios para 
encontrar a intercessão desses recortes, especialmente com relação aos recursos hídricos e à zona costeira, ao confrontar o panorama nacional com o dos estados costeiros, analisando a utilização de critérios físicos na definição de zona costeira. Posteriormente, propostas para o aprimoramento da definição de zona costeira e de critérios complementares à gestão integrada são feitas para cada estado, em face das fragilidades encontradas em cada definição de zona costeira.

\section{INTEGRAÇÃO ENTRE A GESTÁO DE RECURSOS HÍDRICOS E A ZONA COSTEIRA}

No processo brasileiro de gestáo integrada de recursos hídricos e da zona costeira, problemas surgem devido às diferentes unidades geográficas de gestão. Na zona costeira, o gerenciamento não respeita o funcionamento dos sistemas físicos, utilizando os limites municipais como unidade de gestão. A gestão de recursos hídricos utiliza como unidade territorial as bacias hidrográficas, mas não considera a influência marinha nas partes baixas da bacia, no estuário. Tem-se aí o foco do problema aqui estudado, ou seja, instâncias administrativas separadas, porém sob a ótica física do sistema, são elementos indissociáveis (bacia hidrográfica estuário - zona costeira) (Loitzenbauer \& Mendes, 2011).

$\mathrm{Na}$ tentativa de cumprir uma das diretrizes gerais de ação da Política Nacional de Recursos Hídricos (PNRH), a integração da gestão das bacias hidrográficas com dos sistemas estuarinos e zonas costeiras, surgiu no Brasil, em 2005, a CTCOST. A efetividade da CTCOST decorre da proposição de elementos ou aspectos adicionais serem incluídos na regulamentação dos instrumentos da PNRH para o caso de bacias hidrográficas costeiras.

O primeiro instrumento trabalhado foi o Plano de Bacia Hidrográfica, dado o caráter disseminador de diretrizes para os demais instrumentos, bem como de orientação para os comitês de bacia lidarem com os mecanismos de integração entre os sistemas de recursos hídricos e de gerenciamento costeiro. O resultado seria uma resoluçáo do CNRH que estabelece critérios específicos a serem considerados em Planos de Bacias Costeiras. Para que a proposta de resolução possa resultar em consequências práticas, foi incluído um artigo que determina que, para a formulação de diretrizes para o enquadramento dos corpos de água, para a outorga e para a cobrança pelo uso de recursos hídricos, devem ser observadas as especificidades e limitaçôes impostas por diferentes zonas de gestão (Nicolodi et al., 2009). A divisão foi estabelecida considerando os aspectos físicos (geomorfologia, hidrologia etc.) e ecológicos (ecossistemas terrestres e marinhos) e atividades humanas e foi baseada em UNEP/MAP/PAP, 1999.

Salienta-se, as zonas não dizem respeito a zoneamento ou à aplicação de novos instrumentos de gestão. São zonas específicas para a gestão integrada entre a PNRH e PNGC, no plano político, técnico e institucional. A partir dessas zonas de gestão, o critério para a outorga de uso de recursos hídricos deve ser diferenciado nas bacias costeiras, assim como as regras de operação de reservatórios e outras que possam causar interferências no regime hídrico.

Um dos argumentos contra a aprovação da referida resolução é de que essa definição de zonas é mais pertinente ao gerenciamento costeiro do que a gestáo de recursos hídricos. A proposta previa considerar uma zona de influência que possibilitaria integrar bacias contíguas, inclusive aquelas de médio e grande porte. Contudo, ao aumentar a área da bacia hidrográfica até o limite do Mar Territorial, a gestão dos recursos hídricos fica muito mais complexa. Além disso, surge o questionamento sobre como controlar/monitorar a região marinha, considerando que aí existem muitos fatores (marés, ondas, fatores meteorológicos etc.) que estão fora do controle humano. Mesmo com a retirada da definição das zonas de gestão, a proposta de resolução não foi aprovada.

Apesar de ainda não estar aprovada a resoluçáo que estabelece as diretrizes adicionais para elaboração de planos de bacia em zonas costeiras, um segundo instrumento da PNRH está em estudo pela CTCOST, a outorga de direito de uso de recursos hídricos em bacias costeiras. A credibilidade da CTCOST ficou abalada depois da não aprovaçáo da proposta de resoluçáo dos Planos de Bacias Costeiras, e o grupo de estudo da outorga está em andamento desde 2009, sem apresentar resultados. Falta suporte institucional e político à CTCOST, para que as proposiçóes possam ser efetivadas e se tornem normas gerais para a gestão integrada no Brasil.

A análise da definiçâo de zona costeira e o estabelecimento de critérios complementares talvez possa ser uma solução ao problema da gestão integrada no Brasil, visto que, em oito anos de CTCOST, não houve muito progresso. Esse é o objetivo do presente trabalho, analisar as definiçóes de zona costeira utilizadas pelos estados e a definiçáo nacional, propondo critérios complementares, no caso de definiçóes deficientes, visando aprimorar o processo de gestáo costeira integrada, sobretudo entre o gerenciamento costeiro e de recursos hídricos.

\section{A REGIẤO HIDROGRÁFICA ATLÂNTICO SUL}

Considerando que o foco deste artigo é a análise de aspectos físicos na delimitação das fronteiras de gestão da zona costeira e da interface com os recursos hídricos, a área definida para o estudo de caso é considerada com base na definição de bacia hidrográfica. Assim, a área de estudo é a Região Hidrográfica Atlântico Sul, que representa a área de drenagem da margem Atlântica dos estados do sul do Brasil, compreendendo os estados RS, SC e PR e um pequeno trecho do litoral de São Paulo (SP) (Figura 1). Essa unidade de análise foi utilizada com o objetivo de respeitar os limites físicos naturais, ou seja, a bacia hidrográfica.

No PNGC II, há uma alínea que menciona que municípios localizados a até $50 \mathrm{~km}$ da linha de costa podem ser considerados costeiros, desde que possuam em seu território atividades de grande impacto ambiental. Portanto, inclui-se na Figura 1 a delimitação dos $50 \mathrm{~km}$ da linha de costa, visto que é uma área que pode ser incluída na zona costeira nacional pelo critério de impacto ambiental.

A Região Hidrográfica Atlântico Sul (RHAS) destaca-se por abrigar um expressivo contingente populacional, pelo desenvolvimento econômico e por sua importância para o turismo. A região se inicia ao norte, próximo à divisa dos estados de São Paulo e Paraná, e se estende até o arroio Chuí, ao sul. Possui uma área total de $186.080 \mathrm{~km}^{2}$, o equivalente a 


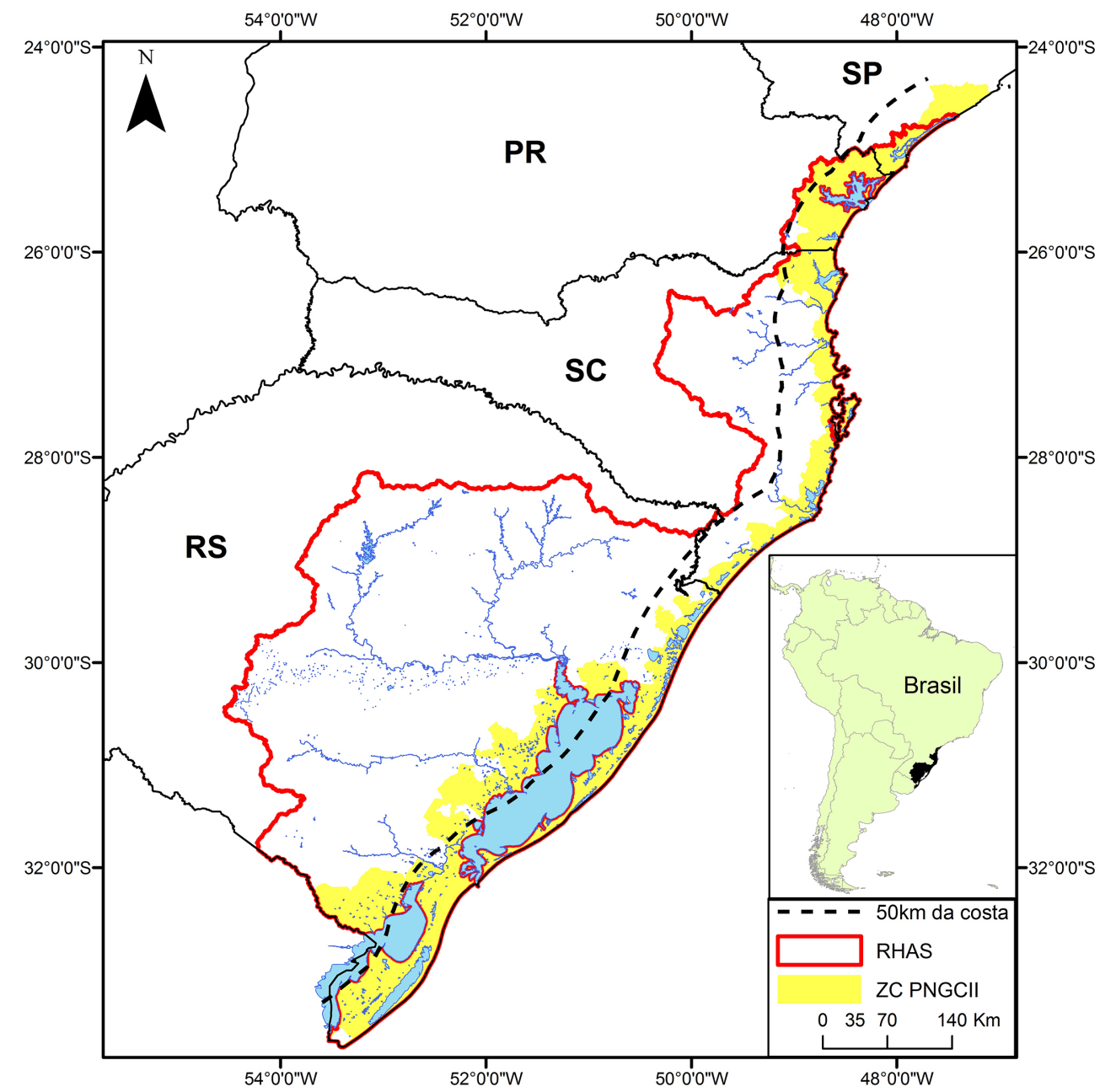

Figura 1. A Regiấo Hidrográfica do Atlântico Sul (RHAS), os municípios considerados costeiros pelo PNGC II e a linha de $50 \mathrm{~km}$ da costa.

Figure 1. South Atlantic Hydrographical Region, the coastal municipalities by the National Plan of Coastal Management II and the $50 \mathrm{~km}$ line from the coast.

2,2\% do País, e abriga 6,8\% da população nacional. A região detém 2,6\% da disponibilidade hídrica do país e exerce 14,6\% da demanda total por recursos hídricos (MMA, 2006).

No contexto socioeconômico da faixa costeira, destacam-se os municípios de Paranaguá, no PR, Joinville e Florianópolis, em SC, e Porto Alegre e Rio Grande, no RS. A região apresenta três grandes complexos portuários: Paranaguá, Itajaí e Rio Grande, e grande importância para o turismo.

Da população de 11,6 milhôes de habitantes, $85 \%$ estão localizados na área urbana, causa da principal problemática ambiental, os esgotos domésticos não tratados. Além da contaminação oriunda dos efluentes gerados pelo esgotamento sanitário, fertilizantes químicos e agrotóxicos provenientes da agricultura, resíduos da suinocultura e efluentes industriais também afetam a qualidade das águas na região. Como área de grande vulnerabilidade ambiental, destaca-se a região de Tubarão (SC), devido à mineraçáo de carvão (MMA, 2006).
As faixas litorâneas da regiấo são caracterizadas pela notória fragilidade ambiental, onde efeitos de intervençóes antrópicas que se apresentem combinados com causas naturais podem levar ao colapso. Exemplos são as enseadas estuarinas localizadas nas cidades de Itajaí, Laguna, São Francisco do Sul (SC) e em Rio Grande, Tramandaí e Torres (RS), que se encontram sob forte pressão antrópica. Principalmente, no entorno das três cidades gaúchas, a qualidade da água está fortemente comprometida pelo lançamento de efluentes domésticos e industriais. Por outro lado, a sobrepesca tem ameaçado os ecossistemas da Laguna dos Patos (RS), da Lagoa Tramandaí (RS) e de Laguna (SC) (MMA, 2006).

O litoral da regiáo sofre pressóes oriundas da presença de população sazonal durante os meses de verão. Nesses meses, a geração de efluentes e a produção de resíduos sólidos aumentam bastante. Em grande parte dos balneários, a estrutura existente não é compatível com esse significativo afluxo de turistas, contribuindo para que se tenha a deterioração da qualidade das águas e a contaminação do 
solo, por despejos irregulares de esgoto e por deficiência na coleta de lixo urbano (MMA, 2006).

Dos estados da região sul, SC se destaca ao apresentar maior adensamento populacional (náo apenas sazonal) e municípios com maiores taxas de crescimento demográfico anual no litoral. As atividades econômicas seguem o crescimento demográfico, especialmente entre Florianópolis e Joinville (Pereira, 2011).

Em todos os estados da RHAS, a outorga de uso dos recursos hídricos - ato administrativo emitido pela União ou pelos Estados que disponibiliza o direito de uso de recursos hídricos - é aplicada em todo o território através da mesma metodologia. O controle qualitativo e quantitativo dos usos da água é possibilitado por meio da outorga. Todavia, em nenhum estado há observação dos impactos causados pelo uso da água na zona costeira e nos estuários.

\subsection{Zona Costeira pelo PNGC II}

A definição de zona costeira apresentada acima, com a Relação dos municípios abrangidos pela faixa terrestre da zona costeira, menciona 75 municípios costeiros na Região Hidrográfica do Atlântico Sul (Figura 1). Entretanto, ao analisar os pontos que caracterizam a zona costeira pelo PNGC II, pelo menos três municípios defrontantes com o mar náo foram mencionados: Balneário Pinhal, no Rio
Grande do Sul (RS), e Balneário Arroio do Silva e Balneário Gaivota, em Santa Catarina (SC). Dois municípios, Turuçu e Capivari do Sul, no RS, são defrontantes com a Laguna dos Patos (logo, contemplam os critérios da Res. CIRM no 005/1997) e não são citados como zona costeira. Salienta-se que Turuçu foi instalado em 1997, no mesmo ano da Res. CIRM 005/1997, por isso não faz parte da relação. Outros dois municípios (Chuí e Arroio do Padre) apresentam todos os seus limites com municípios costeiros, e também não são citados como zona costeira. A Figura 2 exemplifica o caso dos municípios de Turuçu e Arroio do Padre.

Apenas acrescentando os municípios que não foram mencionados, chega-se a 84 municípios que fazem parte da zona costeira. Entretanto, a Região Hidrográfica do Atlântico Sul engloba 413 sedes municipais e um total de 453 municípios (MMA, 2006). Incluir todos esses municípios na definição de zona costeira, com a aplicação dos instrumentos legais e administrativos, tornaria a gestáo muito complexa e difícil. Contudo, o uso do solo na bacia afeta a qualidade ambiental da zona costeira e, de alguma forma, a gestáo e o planejamento da zona costeira devem considerar a bacia hidrográfica.

Além da necessária atualização da Relação dos municípios abrangidospela faixa terrestre da zona costeira, outra análise deve ser feita, com a inclusão do critério da bacia de drenagem. A água é o principal meio físico que interconecta os ambientes,

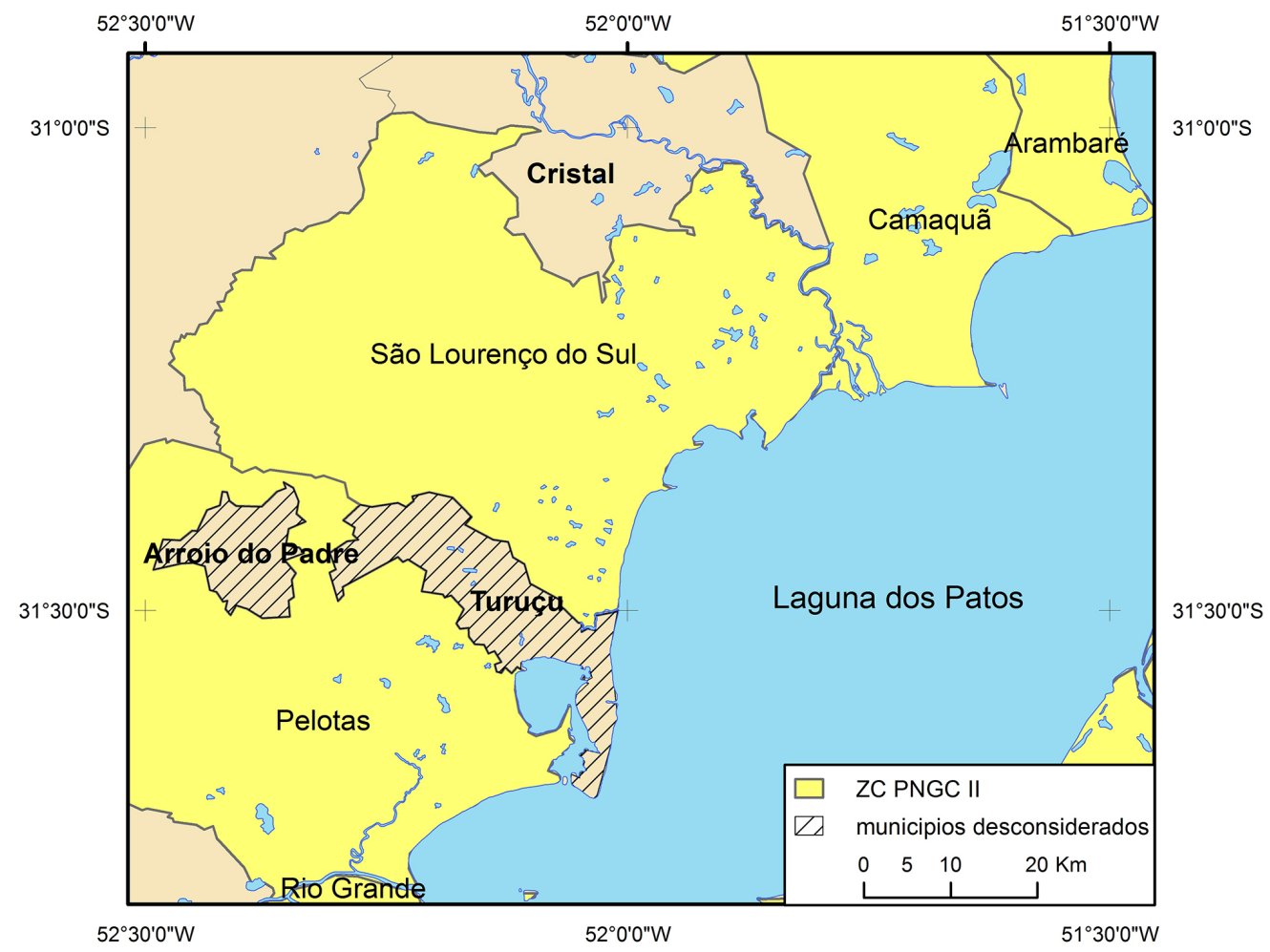

Figura 2. Exemplo de dois municípios não listados na Relação dos municípios abrangidos pela faixa terrestre da zona costeira, mas que se enquadram na caracterização da zona costeira nacional (chamados municípios desconsiderados).

Figure 2. Example of two municipalities that are not listed in the "Relation of the municipalities covered by the terrestrial coastal zone strip" but that fits to the national coastal zone definition. 
transmitindo as consequências de uma atividade para jusante, na zona costeira. Logo, a bacia de drenagem é a área onde a água, através do ciclo hidrológico, flui até atingir o mar.

$\mathrm{Na}$ Figura 2, observa-se o município de Cristal, que não faz parte da definição do PNGC II, mas que está a menos de $20 \mathrm{~km}$ da Laguna dos Patos. Parte do território deste município está tâo próximo da Laguna dos Patos quanto os municípios de São Lourenço do Sul e Pelotas, pertencentes à zona costeira. Além disso, passa pelo território de Cristal o Rio Camaquâ, que é o segundo maior afluente da Laguna, depois do Lago Guaíba. Se uma atividade de grande potencial poluidor estiver localizada no município de Cristal, o impacto na zona costeira seria significativo. Contudo, apesar de estar próximo da Laguna dos Patos, está a mais de $50 \mathrm{~km}$ da linha de costa e, logo, não poderia ser incluído pelo critério de impacto ambiental. A definição nacional não considera de nenhuma forma a bacia de drenagem. Contudo, alguns estados utilizam esse critério. Assim, uma análise mais aprofundada e propostas sáo feitas em nível estadual, visto que é observada uma tendência de utilizar definiçóes mais detalhadas e que consideram a bacia de drenagem nos estados.

\section{2. Área costeira nos estados}

O primeiro Plano Nacional de Gerenciamento Costeiro data de 1988. Apesar de decorrido todo esse tempo, a institucionalização do Gerenciamento Costeiro no Brasil ainda caminha lentamente. Apenas 8 dos 17 estados costeiros apresentavam órgão específico para tratar do assunto e apenas 9 possuíam um plano de gerenciamento costeiro em 2008 (Jablonski \& Filet, 2008).

Nos estados da Regiáo Hidrográfica do Atlântico Sul náo é diferente. Apesar de todos os estados terem algum tipo de Programa de Gerenciamento Costeiro, a aplicação destes na zona costeira ainda é limitada. Dos quatro estados envolvidos, apenas o RS não apresenta um Plano Estadual de Gerenciamento Costeiro (PEGC), apesar de existir desde 1988 o Programa de Gerenciamento Costeiro (GERCO) no âmbito do órgão executivo do meio ambiente, a Fundação Estadual de Proteção Ambiental Henrique Luiz Roessler (FEPAM), que trata de implementar os instrumentos de gestão previstos no PNGC II. Nos outros estados (SC, PR e SP), há leis que instituem os PEGCs.

Ao analisar as legislaçóes que instituem os planos, e, no caso do RS, o GERCO, apenas o estado do PR utiliza a mesma delimitação de zona costeira do PNGC II. Os outros estados possuem sua própria definição, que seguem os mais distintos critérios (Tabela 1), não seguindo as orientaçóes do Dec. Federal $n^{\circ} 5.300 / 2004$, como a de utilizar os limites municipais de definição da área costeira. Isso resulta em duas zonas costeiras diferentes para o mesmo estado, se for considerada a definição estadual e a nacional (Tabela 2).

Observa-se que cada estado utiliza critérios próprios em função do tamanho da área de drenagem para o Atlântico. $\mathrm{O}$ RS possui uma área que drena para o Atlântico extremamente grande e inclui a região hidrográfica do Guaíba (que representa cerca de $30 \%$ do território estadual). Por isso, esta área foi retirada do GERCO, assim como parte das bacias mais ao sul. Já no estado de SP, a área de drenagem Atlântica é menor, e se optou por considerar a totalidade desta como zona costeira. Esse comportamento está relacionado com a complexidade da gestão costeira se a área de abrangência for muito grande. Contudo, alguma intersecçáo entre os recortes da bacia hidrográfica e da definição de zona costeira do PNGC II deve ser feita. O exemplo do RS deve ser analisado com mais atenção, visto que foi encontrado um meio de incluir a bacia de drenagem na definição de zona costeira.

Tabela 1. Definição da zona costeira nos estados da RHAS.

Table 1. Coastal zone definition in the South Atlantic Hydrographical Region states.

\begin{tabular}{ll}
\hline $\begin{array}{l}\text { Instância e instrumentos legais } \\
\text { que definem a zona costeira }\end{array}$ & \multicolumn{1}{c}{ Definiçáo da faixa terrestre } \\
\hline $\begin{array}{l}\text { Rio Grande do Sul (RS) } \\
\text { (FEPAM, s/d) }\end{array}$ & $\begin{array}{l}\text { Náo possui lei que defina. O GERCO delimita a regiáo costeira do RS a } \\
\text { partir de sua formaçáo geológica, relevo e bacia de drenagem. }\end{array}$ \\
\hline $\begin{array}{l}\text { Santa Catarina (SC) } \\
\text { (Lei Estadual N }{ }^{\circ} 13.533 / 2006 \text { e }\end{array}$ & $\begin{array}{l}\text { Pelo conjunto de territórios dos municípios que confrontam com o mar } \\
\text { ou com as grandes lagoas costeiras, ou abrigam ecossistemas costeiros } \\
\text { relevantes e atividades socioeconômicas características da zona costeira; }\end{array}$ \\
\hline $\begin{array}{l}\text { Paraná (PR) } \\
\text { Lei Estadual N }{ }^{\circ} 13.164 / 2001\end{array}$ & $\begin{array}{l}\text { É o espaço geográfico delimitado pelos municípios costeiros. } \\
\text { Compreendendo a planície de inundaçáo fluvio-marinho, constantes dos } \\
\text { ecossistemas de manguezais e de várzea. }\end{array}$ \\
\hline $\begin{array}{l}\text { Sáo Paulo (SP) } \\
\left.\text { Lei Estadual N }{ }^{\circ} 10.019 / 2005\right)\end{array}$ & $\begin{array}{l}\text { Zona costeira é o espaço geográfico delimitado, na área terrestre, pelo } \\
\text { divisor de águas de drenagem atlântica no território paulista. Engloba } \\
\text { todos os ecossistemas e recursos naturais existentes. Considera os } \\
\text { municípios na delimitaçáo da área. }\end{array}$ \\
\hline $\begin{array}{l}\text { Brasil - PNGC II } \\
\text { Res. CIRM No 005/1997 }\end{array}$ & $\begin{array}{l}\text { Formada pelos municípios que sofrem influência dos fenômenos } \\
\text { ocorrentes na zona costeira. }\end{array}$ \\
\hline
\end{tabular}


Tabela 2. Comparação entre os municípios citados como zona costeira pelos estados da RHAS e os municípios costeiros pelo PNGC II, atualizando a Relação dos municipios abrangidos pela faixa terrestre da zona costeira.

Table 2. Comparison among the coastal municipalities by the states and by the National Plan of Coastal Management (PNGC II) updated.

\begin{tabular}{|c|c|c|}
\hline \multicolumn{2}{|r|}{ Faixa Terrestre da ZC pela definiçáo estadual } & \multirow[b]{2}{*}{$\begin{array}{l}\text { PNGC II (atualizado) } \\
\text { Torres, Três Cachoeiras, Arroio do Sal, Três } \\
\text { Forquilhas, Terra de Arreia, Maquiné, Capão } \\
\text { da Canoa, Xangri-lá, Osório, Imbé, Tramandaí, } \\
\text { Cidreira, Balneário Pinhal, Palmares do Sul, } \\
\text { Viamão, Mostardas, Tavares, São José do Norte, } \\
\text { Capivari do Sul, Tapes, Camaquá, Barra do } \\
\text { Ribeiro, Arambaré, São Lourenço do Sul, Pelotas, } \\
\text { Turuçu, Rio Grande, Arroio do Padre, Arroio } \\
\text { Grande, Jaguarão, Santa Vitória do Palmar, Chuí. }\end{array}$} \\
\hline RS & $\begin{array}{l}\text { Torres, Morrinhos do Sul, Três Cachoeiras, Arroio do Sal, } \\
\text { Três Forquilhas, Itati, Terra de Areia, Maquine, Capão da } \\
\text { Canoa, Xangri-lá, Osório, Imbé, Tramandaí, Cidreira, Santo } \\
\text { Antônio da Patrulha*, Balneário Pinhal, Dom Pedro de } \\
\text { Alcântara, Mampituba, São Francisco de Paula*, Palmares } \\
\text { do Sul, Viamão*, Mostardas, Tavares, São José do Norte, } \\
\text { Capivari do Sul, Tapes**, Sentinela do Sul**, Cerro Grande } \\
\text { do Sul**, Camaquã, Barra do Ribeiro*, Arambaré, Cristal, } \\
\text { Sáo Lourenço do Sul, Pelotas, Turuçu, Morro Redondo, } \\
\text { Pedro Osório, Arroio do Padre, Arroio Grande, Capáo } \\
\text { do Leão, Chuvisca, Cerrito**, Rio Grande, Pedro Osório, } \\
\text { Jaguarão**, Rio Grande, Santa Vitória do Palmar; Chuí. } \\
\text { *Município parcialmente dentro da área do GERCO com } \\
\text { sede municipal fora. } \\
\text { ** Municípios parcialmente dentro da área do GERCO com } \\
\text { a sede municipal incluída. }\end{array}$ & \\
\hline SC & $\begin{array}{l}\text { Araquari, Balneário Barra do Sul, Guaruva, Itapoá, Joinville, } \\
\text { São Francisco do Sul e Barra Velha; Balneário Camboriú, } \\
\text { Bombinhas, Camboriú, Itajaí, Itapema, Navegantes, Piçarras, } \\
\text { Penha e Porto Belo; Biguaçu, Florianópolis, Governador } \\
\text { Celso Ramos, Palhoça, São José e Tijucas; Garopaba, Imaruí, } \\
\text { Imbituba, Jaguaruna, Laguna e Paulo Lopes; Araranguá, } \\
\text { Balneário Arroio do Silva, Balneário Gaivota, Içara, Passo de } \\
\text { Torres, Santa Rosa do Sul, São João do Sul e Sombrio. }\end{array}$ & $\begin{array}{l}\text { Araquari, Balneário Barra do Sul, Guaruva, } \\
\text { Itapoá, Joinville, São Francisco do Sul, Barra } \\
\text { Velha, Camboriú, Balneário Camboriú, } \\
\text { Bombinhas, Itajaí, Itapema, Navegantes, Piçarras, } \\
\text { Penha, Porto Belo, Biguaçu, Florianópolis, } \\
\text { Governador Celso Ramos, Palhoça, São José, } \\
\text { Tijucas, Garopaba, Imaruí, Imbituba, Jaguaruna, } \\
\text { Laguna, Paulo Lopes, Araranguá, Balneário } \\
\text { Arroio do Silva, Balneário Gaivota, Içara, Passo } \\
\text { de Torres, Santa Rosa do Sul, São João do Sul, } \\
\text { Sombrio, Capivari de Baixo, Tubarão, Criciúma } \\
\text { e Sangão. }\end{array}$ \\
\hline PR & $\begin{array}{l}\text { Guaraqueçaba, Antonina, Morretes, Paranaguá, Pontal do } \\
\text { Paraná, Matinhos e Guaratuba. }\end{array}$ & $\begin{array}{l}\text { Guaraqueçaba, Antonina, Morretes, Paranaguá, } \\
\text { Pontal do Paraná, Matinhos e Guaratuba. }\end{array}$ \\
\hline SP & $\begin{array}{l}\text { Ubatuba, Caraguatatuba, Ilhabela e São Sebastião, Bertioga, } \\
\text { Guarujá, Cubatão, Santos, São Vicente, Praia Grande, } \\
\text { Mongaguá, Itanhaém e Peruíbe; Apiaí, Barra do Chapéu, } \\
\text { Barra do Turvo, Cajati, Eldorado, Iporanga, Itaóca, } \\
\text { Itapirapuã Paulista, Itariri, Jacupiranga, Juquiá, Juquitiba, } \\
\text { Miracatu, Pariquera-Açu, Pedro de Toledo, Registro, Ribeira, } \\
\text { São Lourenço da Serra, Sete Barras e Tapiraí, Iguape, } \\
\text { Cananéia e Ilha Comprida. }\end{array}$ & $\begin{array}{l}\text { Ubatuba, Caraguatatuba, Ilha Bela, São } \\
\text { Sebastião, Bertioga, Guarujá, Cubatão, Santos, } \\
\text { São Vicente, Praia Grande, Mongaguá, Itanhaém, } \\
\text { Peruíbe, Iguape, Cananéia e Ilha Comprida. }\end{array}$ \\
\hline
\end{tabular}

Como já está ocorrendo na prática, apesar de o PNGC II não incluir critérios físicos nos limites da zona de gestão costeira, alguns estados estão incluindo (como SP e RS). Talvez a solução para a inclusão dos processos físicos, como a bacia de drenagem, deva ser feita a partir dos estados.

\section{a) Rio Grande do Sul (RS)}

No RS, os critérios utilizados (incluindo a bacia de drenagem) determinam uma zona costeira maior que a proposta pelo PNGC e que, ao mesmo tempo, não considera os limites municipais. Assim, há a presença de municípios parcialmente localizados na zona costeira, como, por exemplo, o município de São Francisco de Paula (Figura 3). Também há municípios que são considerados costeiros pelo PNGC II e que, na definição estadual, estão contabilizados apenas em parte (Figura 3).

Em contraposição à definição nacional e à orientação do Dec. Federal n ${ }^{\circ} 5.300 / 2004$, a delimitação costeira no RS observa os processos físicos atuantes ao utilizar a bacia de drenagem; contudo, ao não observar os limites municipais, questiona-se a efetividade da delimitação utilizada. $\mathrm{Na}$ aplicação de políticas públicas em um município parcialmente 


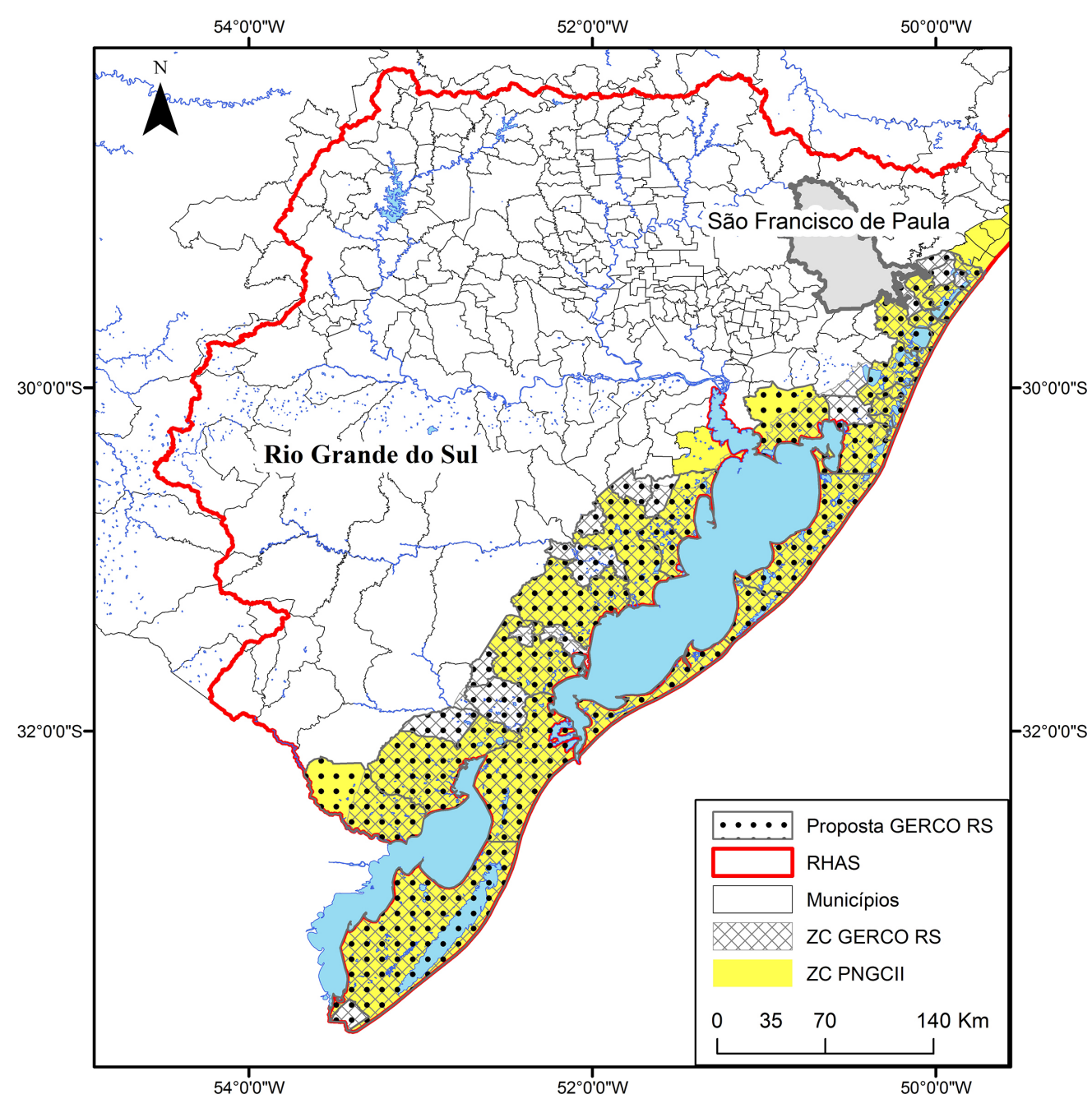

Figura 3. Delimitaçóes da faixa terrestre da zona costeira no Rio Grande do Sul (RS) e a proposta de uma nova definição. Em cinza, o município de São Francisco de Paula, que pertence apenas em parte à zona costeira pelo GERCO-RS, mas que não faz parte pelo PNGC II.

Figure 3. Delimitations of the terrestrial strip of the coastal zone in the state of Rio Grande do Sul (RS) and a proposal for a new definition. In gray the municipality of Säo Francisco de Paula, which belongs to the coastal zone in part (in the state definition) and in the national level it does not.

costeiro, há a necessidade de divisão do território para aplicação de diferentes legislaçôes. Ou seja, não será possível aplicar os mesmos instrumentos e a mesma legislação em todo o território municipal. O município deverá ter um plano municipal de gerenciamento costeiro que só será válido para parte do território.

O estado do RS deve incluir o critério da área dos municípios na zona costeira e respeitar o artigo $5^{\circ}$ do Dec. Federal $n^{\circ} 5.300 / 2004$, que estabelece os princípios fundamentais da gestão da zona costeira. Uma solução para a definiçáo de zona costeira no estado do RS seria arredondar a área costeira do GERCO/RS para que considere a totalidade dos municípios. Uma proposta seria que municípios com mais de $50 \%$ da área dentro da zona costeira fossem considerados como tal e municípios com menos de $50 \%$ de área fossem desconsiderados. Assim, seriam excluídos, na definiçáo estadual, os municípios de Cerrito, Sertão Santana, Barra do Ribeiro, Santo Antônio da Patrulha e São Francisco de Paula. Além disso, os municípios de Jaguarão e Viamão seriam considerados costeiros em sua totalidade (Figura 3).

b) Santa Catarina (SC)

O estado de SC possui uma situaçáo próxima à do RS, com uma grande bacia de drenagem para o Atlântico. Contudo, a definiçáo de zona costeira estadual, além de não acrescentar nenhum critério físico, ainda diminui a área definida pelo PNGC II (Figura 4). Ao excluir municípios que não estão localizados na linha de costa, mas que apresentam atividades de grande impacto ambiental (Sangão, Tubarão, Capivari de Baixo e Criciúma, que possuem indústrias de mineração de carvão), a qualidade da zona costeira pode ficar comprometida. $\mathrm{O}$ conceito de bacia hidrográfica ou área de drenagem deveria ser integrado de alguma forma à definição estadual de zona costeira em SC.

Uma proposta seria que, pelo menos, o estado de SC utilizasse a definição nacional, incluindo os municípios de Criciúma, Sangão, Capivari de Baixo e Tubarão na zona costeira. Além disso, de forma a integrar as políticas 


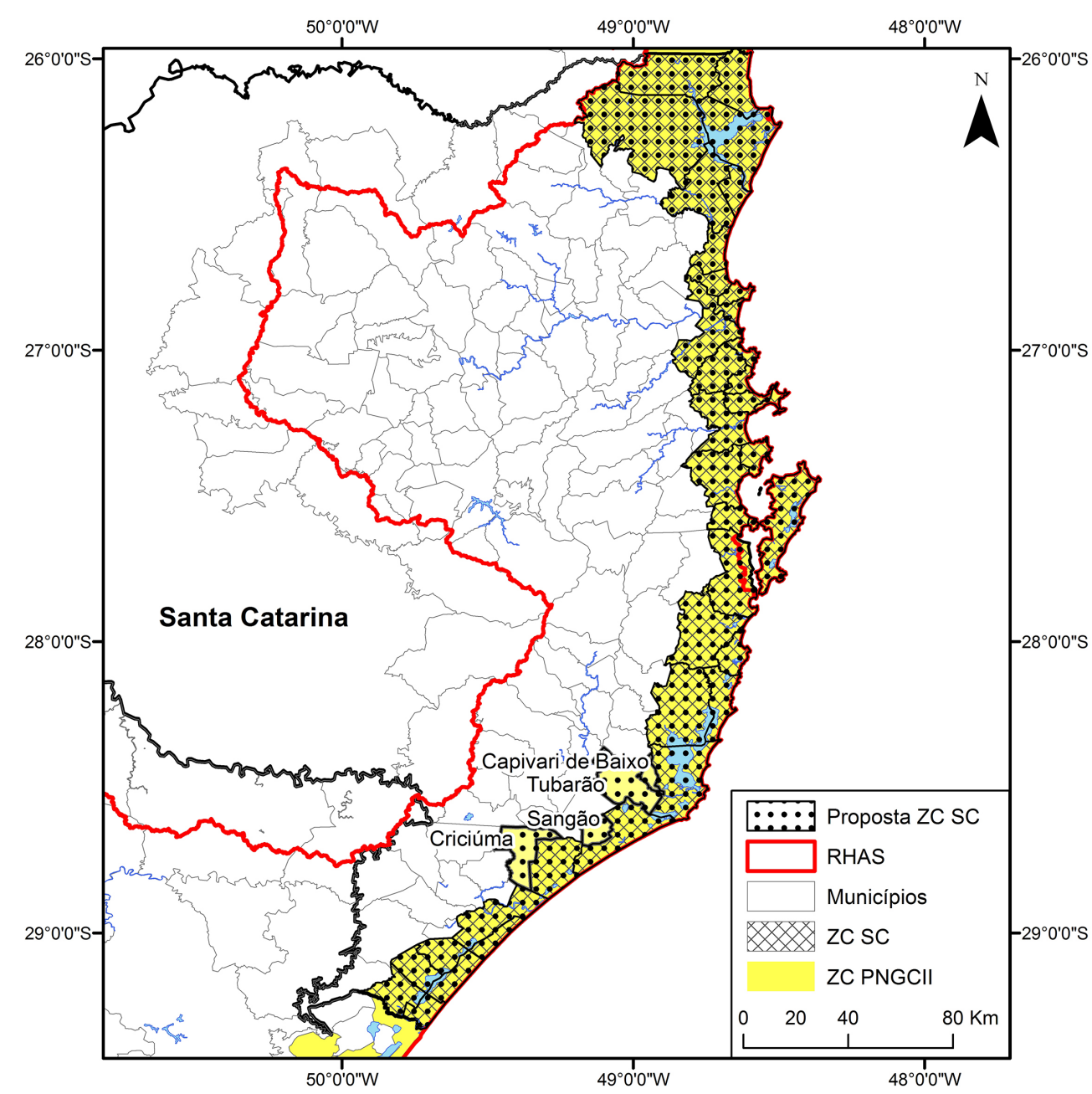

Figura 4. Definição de zona costeira pelo estado de Santa Catarina (SC), pelo PNGC II, e a proposição de uma nova zona costeira estadual. Ressalta-se a situação dos municípios de Tubarão, Sangão, Capivari de Baixo e Criciúma, que pertencem à zona costeira nacional, mas náo à estadual.

Figure 4. Coastal zone definition in the state of Santa Catarina (SC), in the national level and a proposal for a new coastal zone definition. We highlight the plight of the municipalities of Tubaräo, Sangão, Capivari de Baixo e Criciuma, which belong to the national coastal zone but do not in the state level.

ambientais (recursos hídricos, gerenciamento costeiro e meio ambiente) e incluir as relaçóes de causa e efeito entre o uso da terra na bacia e a qualidade ambiental costeira, uma área de influência costeira poderia ser criada. Essa área seria definida em função da dinâmica física e da bacia de drenagem, não pertencendo à zona costeira propriamente dita.

Essa zona teria uma estratégia de gestão diferente, para facilitar o processo de gerenciamento. Não estando sujeita às implicaçóes de ser considerada como zona costeira - como, por exemplo, conter um plano municipal de gerenciamento costeiro e aplicação de todos os outros instrumentos de gestão costeira -, a gestão seria mais prática. No processo de gestão integrada, essa zona consideraria as implicaçóes do uso da terra e dos recursos hídricos através da aplicação específica dos instrumentos de gestão ambiental (por exemplo, o licenciamento ambiental) e de recursos hídricos (como a outorga), considerando particularidades da localização próxima à zona costeira.
Do ponto de vista da quantidade hídrica, a diminuição da vazão de água doce que chega aos estuários é a principal consequência dos projetos de aproveitamento de recursos hídricos (Olsen et al., 2006; Kennish, 2002). Essa diminuição da afluência pode aumentar os impactos da contaminação, da sobrepesca e da destruição de habitats, além de limitar a abundância de água doce na costa (Olsen et al., 2006). A outorga de uso dos recursos hídricos é uma ferramenta necessária para gerir esse problema. Na zona de influência costeira, a outorga deverá considerar a dinâmica da salinidade (relação entre a variação na descarga de água doce e a intrusão salina no estuário). O estado americano do Texas é um exemplo da utilização dessa metodologia. Há previsão na Lei das Águas estadual que a outorga de uso da água para armazenamento, retirada ou derivação a até 200 milhas (aproximadamente $322 \mathrm{~km}$ ) a montante da boca do estuário deve observar as consequências para as baías ou os estuários (Texas Water Code, 2009). 
A água de má qualidade, poluentes e resíduos sólidos que são lançados na bacia hidrográfica acabam na zona costeira e no oceano por ação do próprio ciclo hidrológico. Várias ferramentas de gestão existem para gerir essa problemática da qualidade ambiental. $\mathrm{Na}$ zona de influência costeira, o licenciamento ambiental e a outorga qualitativa aparecem como instrumentos ideais para gerir o lançamento de efluentes na bacia hidrográfica que podem afetar a zona costeira. Empreendimentos de relevante impacto ambiental, que necessitem de EIA/RIMA para sua instalação, deverão observar as implicaçóes deste na zona costeira em toda a área da zona de influência. A outorga qualitativa deve observar quanto do efluente lançado irá se conservar até atingir a zona costeira ou o quanto irá impactá-la. A montante da zona de influência costeira, a outorga continuaria a observar a vazão de referência, e o licenciamento ambiental não precisaria considerar as relaçóes com a zona costeira. A jusante, na zona costeira, o território estará sujeito às implicaçôes do gerenciamento costeiro (PNGC), e a gestáo de recursos hídricos e ambientais deve considerar a interação com a zona costeira, da mesma forma que na zona de influência.

Uma proposta para a delimitação dessa zona de influência costeira seria utilizar a definiçấo de estuário (Kjervje, 1987) - que delimita o limite superior do estuário em funçáo da propagação da onda de maré. Assim, a zona de influência seria a área entre a zona costeira (municípios costeiros do PNGC II) e o limite superior do estuário (Figura 5).

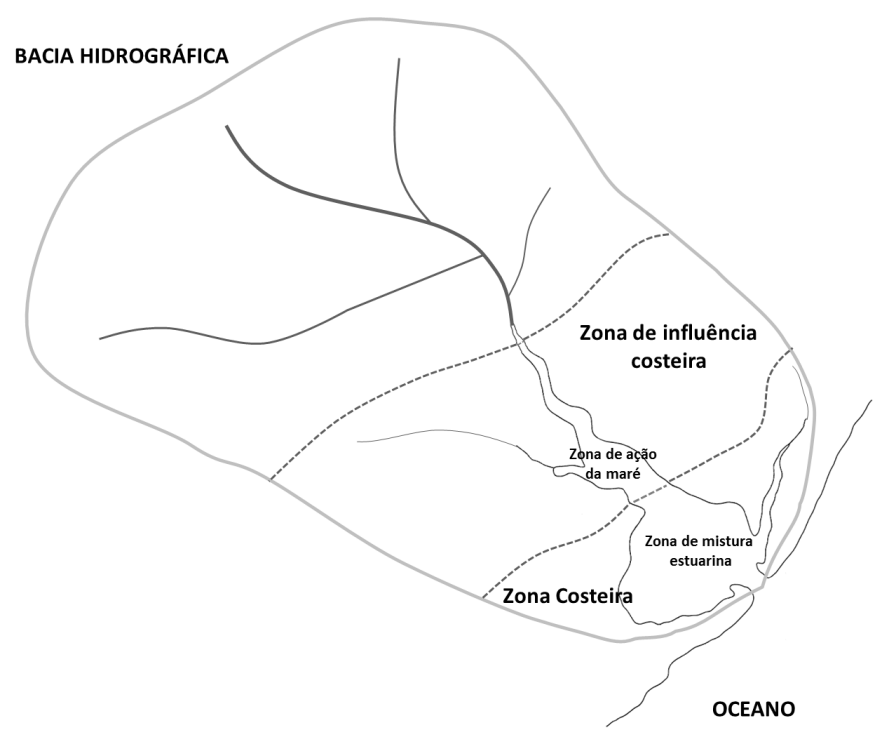

Figura 5. Esquema da delimitação da zona costeira e da zona de influência costeira a partir da definição de estuário de Kjerfve (1987). Adaptado de Kjerfve (1987).

Figure 5. Scheme of the coastal zone and the zone of coastal influence based on Kjerfue (1987) estuary's definition. Adapted from Kjerfue (1987).

\section{c) Paraná (PR)}

No estado do PR, a definiçáa de zona costeira segue a diretriz nacional (PNGC II). Uma porção muito pequena do estado drena para a costa paranaense, sendo que grande parte escoa para a bacia do Rio da Prata. Logo, seria interessante que este estado utilizasse como definição de zona costeira toda a área de drenagem, ou seja, toda a parte da Regiáo Hidrográfica do Atlântico Sul pertencente ao estado. Isso acrescentaria dois municípios à zona costeira: São José dos Pinhais e Tijucas do Sul (Figura 6).

Contudo, os municípios de São José dos Pinhais e Tijucas do Sul possuem menos de 50\% de seu território pertencente à RHAS e com a maior parte dele localizado na regiâo do Planalto Paranaense. Considerando a complexidade que seria agregada ao gerenciamento costeiro e o pequeno impacto do território na bacia de drenagem atlântica, conclui-se que não seria ideal acrescentar esses municípios, que fazem parte da regiâo metropolitana de Curitiba (capital).

Outro ponto a ressaltar é que o estado do PR possui parte do seu território (municípios em cinza na Figura 6) não pertencente à RHAS, mas à Região Hidrográfica do Atlântico Sudoeste, que drena primeiramente para o estado de SP e, posteriormente, deságua no Atlântico no norte de SP, já região do Atlântico Sudoeste. Esses municípios, em geral, pertencem à região metropolitana de Curitiba, embora a capital pertença à drenagem da bacia do Paraná. Devido à complexidade que seria acrescentada à gestão ambiental, esta área não deve ser acrescentada à definiçấo de zona costeira. Além disso, esses municípios estão mais distantes do oceano e, assim, a influência das atividades aí localizadas na zona costeira não é mais direta. Dessa forma, a gestão ambiental desta área segue as normas da Política Nacional de Meio Ambiente e de Recursos Hídricos, sem considerar o impacto na zona costeira. Assim, a definição estadual de zona costeira do estado do PR é considerada aceitável e não necessita de modificaçóes.

\section{d) São Paulo}

Foi analisada toda a zona costeira estadual, mesmo a porção pertencente à Região Hidrográfica do Atlântico Sudoeste. $\mathrm{O}$ estado de SP utiliza, na sua definição, toda a área que exerce influência na zona costeira estadual (Figura 7), utilizando o conceito de divisor de águas de drenagem atlântica estadual. Como esta não determina uma porcentagem extensa do território paulista, mostrou-se prática e aplicável.

Contudo, ao confrontar os municípios costeiros com o divisor de águas de drenagem atlântica estadual, alguns municípios não são considerados como zona costeira, apesar de estarem do lado de dentro do divisor de drenagem. Isso pode ser justificado por apenas uma fração desses municípios estarem do lado de dentro do divisor de drenagem, o que não justificaria as implicaçóes de serem considerados como zona costeira. Esses municípios fazem parte da região metropolitana de São Paulo, incluindo até a capital. Ou, talvez, isso ocorra em virtude de erros inerentes às diferentes bases de dados geográficos e aproximaçôes na definição de bacias de drenagem (Figura 7).

De qualquer maneira, o estado de São Paulo utiliza uma definição adequada de zona costeira, e, dos estados analisados, é a que melhor observa os critérios físicos - diga-se, a bacia de drenagem, pois mescla esse critério com a utilizaçáo dos municípios como unidade de gestão. Contudo, a definiçấo se aplica bem ao território do estado, não podendo ser aplicada 


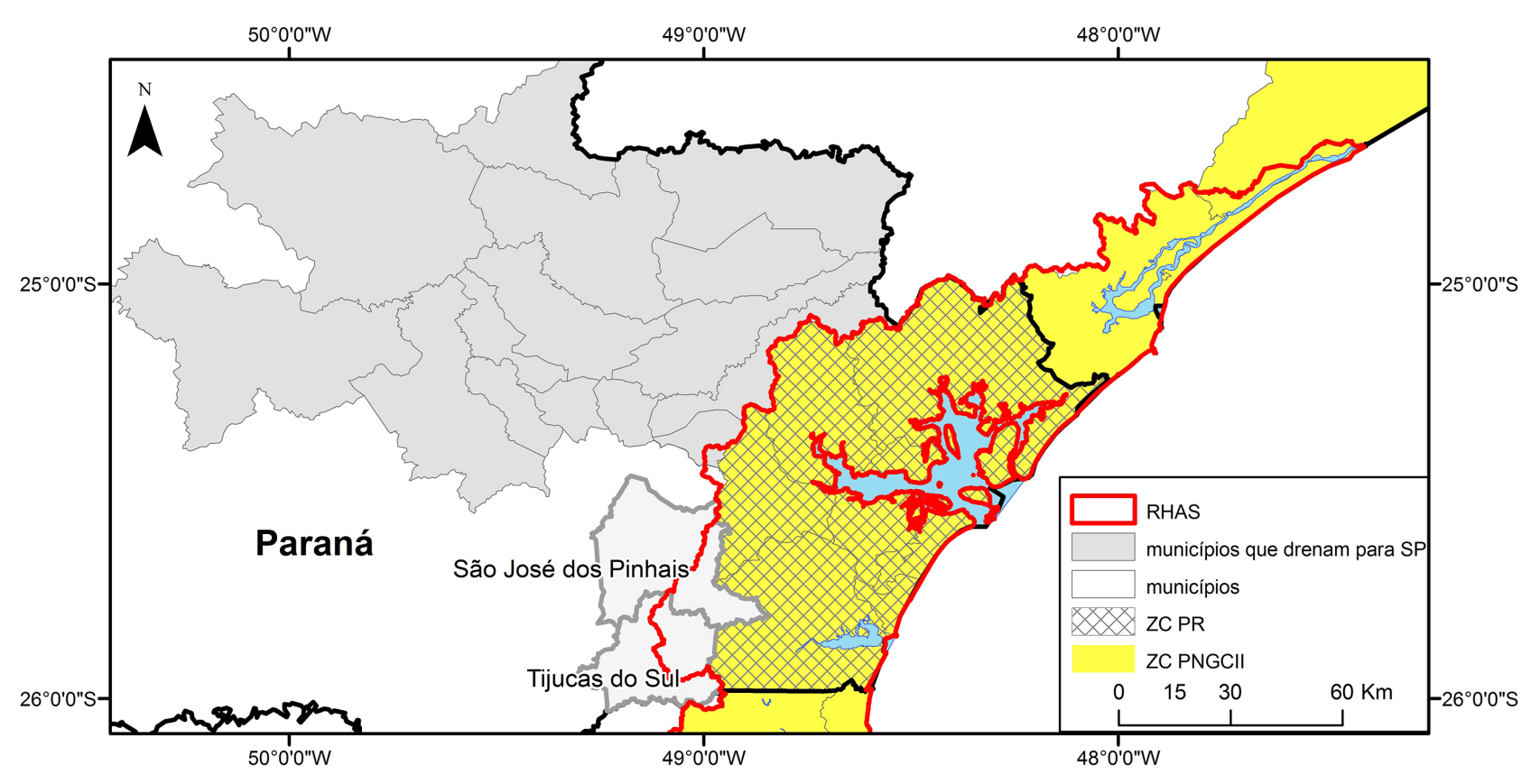

Figura 6. Zona costeira no estado do Paraná, os dois municípios que pertencem à RHAS, mas não à zona costeira (São José dos Pinhais e Tijucas do Sul); e os municípios que drenam para o estado de São Paulo (SP) e, posteriormente, ao Atlântico.

Figure 6. Coastal zone in the state of Paraná, the two municipalities that belongs to the basin area but not to the coastal zone (São José dos Pinhais e Tijucas do Sul), and the municipalities that drain to the state of Sáo Paulo (SP) and then to the Atlantic.

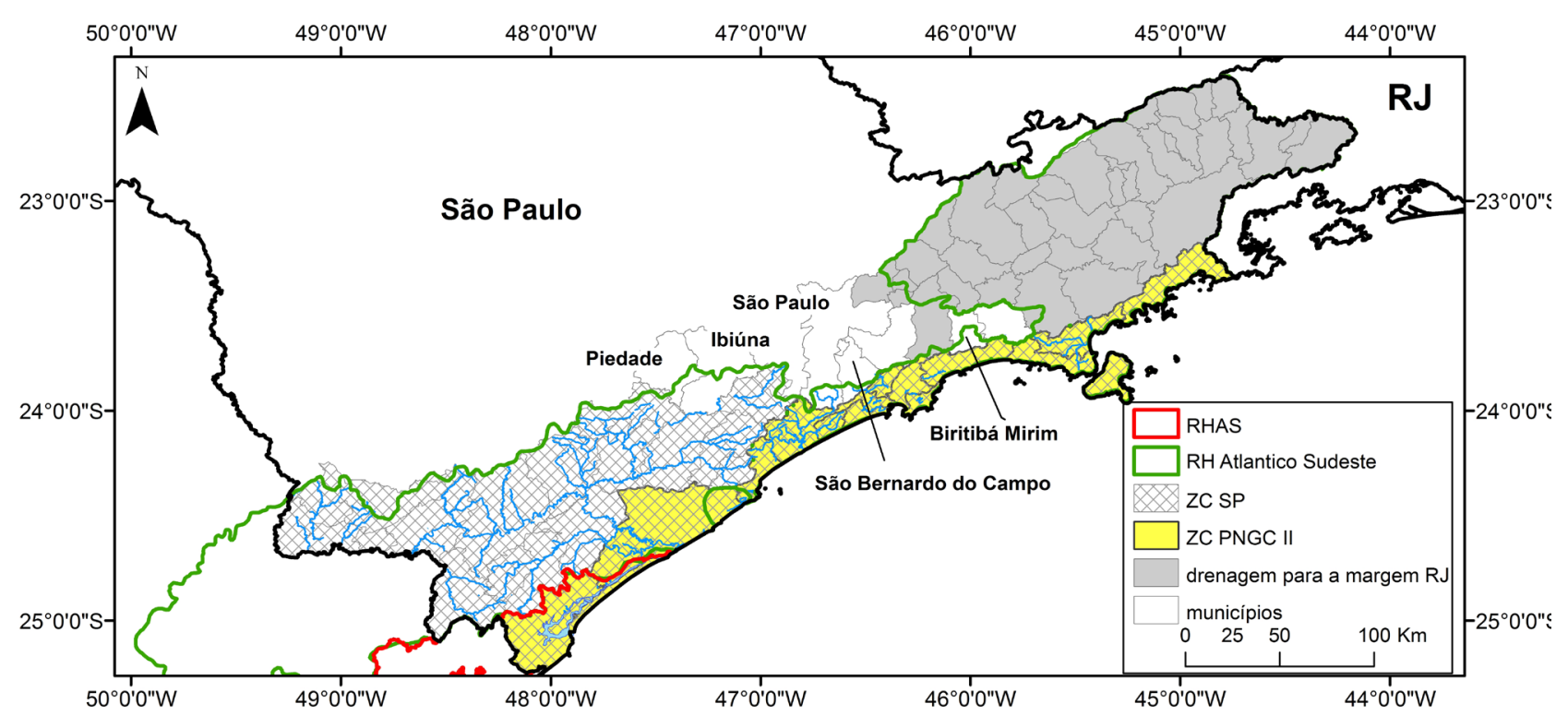

Figura 7. A zona costeira do estado de São Paulo (SP), a do PNGC II e os municípios que drenam para o estado do Rio de Janeiro e, posteriormente, para o Atlântico.

Figure 7. Coastal zone in the state of São Paulo (SP), in the National Plan for Coastal Management (PNGC II, in Portuguese) and the municipalities that drain to the state of Rio de Janeiro (RJ) and then to the Atlantic Ocean. 
a todos os estados costeiros em virtude do tamanho da bacia de drenagem atlântica de outros estados.

O estado de Sáo Paulo apresenta a mesma particularidade do estado do Paraná, possuindo uma área que drena para o estado do Rio de Janeiro e, posteriormente, para o oceano Atlântico (em cinza na Figura 7). A proposição para esses municípios é a mesma do Paraná, que sigam as normas gerais de gestáo ambiental e de recursos hídricos, sem as particularidades de interação com a zona costeira. Da mesma forma do Paraná, considera-se que o estado de São Paulo não necessita modificar a sua definição de zona costeira, sendo a atual considerada aceitável.

\section{CONCLUSÃO}

Considerando a importância das fronteiras de gestão para o manejo sustentável dos recursos naturais, a delimitação da zona costeira deve incluir os processos físicos - principalmente o critério da bacia hidrográfica.

Ao observar e confrontar os limites de zona costeira no Brasil com os limites estaduais, observa-se que há subjetividade nessa delimitação. Alguns estados consideram a bacia de drenagem, outros não. Mas o tamanho do território estadual (ou nacional), assim como a área que drena para o Atlântico, são fatores considerados na definição de zona costeira. Isso ocorre porque não se quer que a grande parte do estado seja considerada costeiro, mas a área que mais intensamente influencia ou é influenciada pela zona costeira.

A definição estadual deve ser mais específica que a nacional. Observa-se uma tendência em utilizar definiçóes específicas em função da bacia de drenagem para o oceano, os estados do Rio Grande do Sul e São Paulo são exemplos disso. Contudo, nas definiçóes estaduais observadas, não há nenhuma que possa se expandir para ser utilizada em outros estados. Cada um cria uma zona costeira em virtude das suas características particulares, que diferem de um estado para outro.

A definição utilizada pelo estado de São Paulo é bem abrangente e ideal, incluindo os critérios de bacia de drenagem e municípios. Ideal para o estado, mas não aplicável em todo o território nacional. A gestão costeira ficaria muito complexa, com vários instrumentos adicionais de gestão do território, se fosse aplicada esta metodologia no Rio Grande do Sul ou em Santa Catarina, que possuem uma ampla bacia de drenagem para o Oceano Atlântico, por exemplo. A metodologia do Paraná também se mostrou ideal para o seu território e seus processos físicos.

O Rio Grande do Sul definiu a sua zona costeira de forma que englobou os processos físicos e não obteve uma área extremamente grande. A única consideração é que este deve incluir o critério dos limites municipais na zona costeira para se adequar à diretiva nacional.

O estado de Santa Catarina foi o que não incluiu de nenhuma maneira (mesmo indireta) os processos físicos na sua definição de zona costeira. Uma proposição para uma zona de influência costeira visa suprir a lacuna existente na definição, visando ser uma zona de gestáo integrada de recursos hídricos e da zona costeira. Trabalhos futuros devem considerar essa proposição e aplicá-la no estado. Além disso, sugere-se que o estado de Santa Catarina inclua os municípios considerados costeiros pelo PNGC II na sua definição estadual.

A partir deste estudo, conclui-se que, em algumas situaçóes (Rio Grande do Sul, Paraná e São Paulo), a gestão integrada de recursos hídricos e da zona costeira deve ser feita apenas na área considerada como zona costeira pelos estados. Nessa parte do território, as relaçóes de causa e efeito entre o uso da terra e dos recursos hídricos e a zona costeira devem ser observadas. Por exemplo, critérios específicos para outorga e licenciamento ambiental devem ser aplicados, como já mencionado acima. No caso de Santa Catarina, além da zona costeira, uma zona um pouco mais ampla deve considerar essa interação, além da própria zona costeira, visto que esta é muito pequena em virtude da bacia que drena para o Atlântico e das atividades antrópicas localizadas próximas à costa. Assim, no estado de Santa Catarina, a inclusão de uma zona de influência costeira tem como objetivo de ser uma área onde as políticas de meio ambiente e recursos hídricos observam os impactos que podem causar na zona costeira, sem ser zona costeira, ou seja, sem estar sob as normas do PNGC II.

Em estudos futuros, a análise feita deve ser estendida a todos os outros estados costeiros brasileiros, visando apresentar e aprimorar o panorama nacional das fronteiras de gestão costeira integrada.

\section{REFERÊNCIAS BIBLIOGRÁFICAS}

Beatley, T.; Brower, D.J.; Schwab, A.K. (2002) - An Introduction to Coastal Zone Management. 352p., Island Press, Washington, DC, U.S.A. ISBN: 9781559639156.

Clark, J.R. (1996) - Coastal Zone Management Handbook. 720p., Lewis Publishers, New York, NY, U.S.A. ISBN: 978-156670092.

Genz, F.; Lessa, G.C.; Cirano, M. (2008) - Vazão Mínima para Estuários: Um caso no Rio Paraguaçu/ BA. Revista Brasileira de Recursos Hídricos (ISSN 2318-0331), 13(3):73-82, Porto Alegre, RS, Brasil. Disponível em http://www.abrh.org.br/SGCv3/UserFiles/ Sumarios/a7f66c99aad323b5e031a87058f1b745_ d08ee46b14f2e9894fab5c658ca387fe.pdf

Jablonski, S.; Filet, M. (2008) - Coastal management in Brazil - A political riddle. Ocean \& Coastal Management, 51(7):536-543. DOI: 10.2112/06-0723.1

Kennish,M.J.(2002)-Environmentalthreatsandenvironmental future of estuaries. Environmental Conservation, 29(1):78107. DOI: $10.1017 / S 0376892902000061$

Kjerfve, B. (1987) - Estuarine Geomorphology and Physical Oceanography. In: J.W. Day Jr., C.H.A.S. Hall, W.M. Kemp, A. Yáńez-Aranciba, (eds.), Estuarine Ecology, pp.47-78, Wiley, New York, NY, U.S.A. ISBN: 9780471062639 .

Lindeboom, H.; van Kessel, J.G.; Berkenbosch, L. (2005) Areas with special ecological values on the Dutch Continental Shelf. 103 p., Rijkwaterstaat, Den Haag, Netherlands. ISBN: 90-369-3415-X. http://edepot.wur.nl/3249

Loitzenbauer, E.; Mendes, C.A.B. (2011) - A dinâmica da salinidade como uma ferramenta para a gestão integrada de recursos hídricos na zona costeira: uma aplicação à 
realidade brasileira. Revista de Gestâo Costeira Integrada, 11(2):233-245. DOI: $10.5894 / \mathrm{rgci} 248$

Loitzenbauer, E.; Mendes, C.A.B. (2012) - Salinity dynamics as a tool for water resources management in coastal zones: $\mathrm{Na}$ application in the Tramandaí River basin, southern Brazil. Ocean \& Coastal Management, 55:52-62. DOI: 10.1016/j.ocecoaman.2011.10.011

MMA (2006) - Caderno da Regiāo Hidrográfica Atlântico Sul. 128p., Ministério do Meio Ambiente, Secretaria dos Recursos Hídricos, Brasília, DF, Brasil. ISBN: 85-7738062-9.

MMA (2008) - Macrodiagnóstico da Zona costeira e Marinha do Brasil. 241p., Ministério do Meio Ambiente, Brasília, Brasil. ISBN: 978-8577381128.

Monteiro, P.M.S.; Marchand, M. (2009) - Catchment2Coast: A systems approach to coupled river-coastal ecosystem science and management. 92p., Deltares Select Series Vol. 2, IOS Press, Amsterdam, Países Baixos. ISBN: 9781607500308.

Nicolodi, J.L.; Zamboni, A.; Barroso, G.F. (2009) - Gestão Integrada de Bacias Hidrográficas e Zonas Costeiras no Brasil: Implicaçốes para a Região Hidrográfica Amazônica. Revista de Gestão Costeira Integrada, 9(2):932. DOI: $10.5894 /$ rgci1 15

Olsen, S.B.; Padma, T.V.; Richter, B.D. (2006) - Guia para el Manejo del Flujo de Agua Dulce a los Estuarios. 44p., USAI, The Nature Conservancy, The Coastal Resource Center e University of Rhode Island, Washington, DC, U.S.A. Disponível em http://pdf.usaid.gov/pdf_docs/ PNADI095.pdf

Pereira, R.M.FA (2011) - Expansão urbana e turismo no litoral de Santa Catarina: o caso das microrregióes de Itajaí e Florianópolis. Interaçôes 12(1):101-111. DOI: 10.1590/S1518-70122011000100010

Sorensen, J.C.E; McCreary, S.T. (1990) - Institutional Arrangements for Managing Coastal Resources and Environments. 194p., Coastal Management Publications No. 1. NPS/US AID Series, National Park Service, Office of International Affairs, Washington, DC, U.S.A. ISBN: 978-0931531002.

UN (1982) - United Nations Conference on the Law of the Sea. 208p., United Nations, Montego Bay, Jamaica. http://www.un.org/depts/los/convention_agreements/ texts/unclos/unclos_e.pdf

UNEP/MAP/PAP, (1999) - Conceptual Framework and Planning Guidelines for Integrated Coastal Area and River Basin Management. 78p., Priority Actions Programme, UNEP, Split, Croácia. ISBN: 953-6429-27-69. http://www.pap-thecoastcentre.org/pdfs/ICARM\%20 Guidelines.pdf

\section{LEGISLAÇÃO CITADA}

Resoluçáo CIRM No 005/98. Aprova o Plano Nacional de Gerenciamento Costeiro II (PNGC II). Publicado no DOU, de 14/01/1998, pp. 36-37. Disponível em http://www.dern.ufes.br/gc/Plano\%20Nacional\%20de\%20 Gerenciamento\%20Costeiro\%20II.pdf

Resolução CONAMA N001/86. Dispóe sobre critérios básicos $e$ diretrizes gerais para a avaliação de impacto ambiental. Publicado no DOU, de 17/02/1986, pp. 2548-2549. Disponível em http://www.mma.gov.br/port/conama/res/ res86/res0186.html

Texas Water Code, 2009. Subtitle B: Water Rights. pp.195-329, Austin, TX, U.S.A. Disponível em http://www.statutes.legis. state.tx.us/Docs/SDocs/WATERCODE.pdf.

\section{WEB SITES}

FEPAM, (s/d) - Programa de Gerenciamento Costeiro GERCO/RS. FEPAM, Fundação Estadual de Proteção Ambiental Henrique Luis Roessler, Porto Alegre, RS, Brasil. In: http://www.fepam.rs.gov.br/programas/gerco.asp (acedido em Outubro de 2013) 